\title{
Right ventricular-pulmonary artery connection in stage 1 palliation of hypoplastic left heart syndrome
}

Jeffrey M. Pearl, MD

See related article on page 1378.

From the Department of Cardiothoracic Surgery, Children's Hospital Medical Center, Cincinnati, Ohio.

Received for publication Feb 12, 2003; accepted for publication March 4, 2003

Address for reprints: Jeffrey M. Pearl, MD, the Department of Surgery, Children's Hospital Medical Center, 3333 Burnet Ave, OSB-3, Cincinnati, OH 45229 (E-mail: pearj0@chmcc.org).

J Thorac Cardiovasc Surg 2003;126: $1268-70$

Copyright () 2003 by The American Association for Thoracic Surgery

$0022-5223 / 2003 \$ 30.00+0$

doi:10.1016/j.jtcvs.2003.03.001

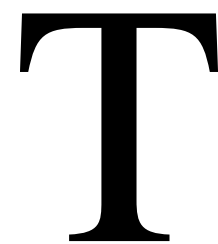

he Norwood procedure has undergone numerous modifications since its original description. ${ }^{1}$ The term "modified" Norwood now applies to several variations both in the reconstructive techniques and in the conduct of bypass. ${ }^{2,3}$ Surgeons now have available technical modifications that can be applied to the variable anatomy encountered within the complex spectrum of hypoplastic left heart syndrome. Of equal importance to the technical advances, better understanding of the Norwood physiology and improved postoperative management have resulted in improved outcomes. ${ }^{4-6}$ In fact, it is difficult to separate the technical aspects from the physiologic as, more than in any other lesion, the two are interdependent.

Perhaps one of the most critical observations made regarding post-Norwood physiology was the concept of pulmonary over-circulation and balancing the systemic/pulmonary flow (Qp/Qs) ratio. ${ }^{5,7}$ Initial surgical response to increased understanding of this phenomenon included the use of smaller shunts, with a $3.5-\mathrm{mm}$ shunt being used for most infants and even a 3.0-mm shunt for those weighing less than $3.0 \mathrm{~kg} .{ }^{8}$ Despite a more favorable Qp/Qs ratio with the use of smaller shunts, the fact that the shunt in a typical Norwood procedure comes off a systemic vessel unavoidably results in diastolic runoff and lower diastolic pressure. In addition, using a "one size fits all" approach can result in significant variation in saturations and hemodynamics because of other variables such as size of the patient, size of the feeding vessel, overall cardiac output, and pulmonary vascular resistance. Hence, inadequate systemic perfusion as a result of increased Qp/Qs and significant cyanosis related to a decreased $\mathrm{Qp} / \mathrm{Qs}$ are not uncommon in the early postoperative period. The management of these patients can be quite complex and unfortunately not always successful. In addition, concern has been raised regarding the effect of the diastolic runoff in terms of both short-term and long-term coronary blood flow, although no evidence exists that myocardial perfusion is significantly affected by the classic shunt physiology. Nonetheless, the not infrequent progressive myocardial failure seen in some patients after palliation for hypoplastic left heart syndrome raises concern about coronary perfusion as a potential cause.

The importance of balancing shunt flow is so critical that placement of an adjustable snare around the shunt ${ }^{9}$ or placement of hemaclips ${ }^{10}$ has been tried. However, the potential risks of shunt thrombosis when snares are used, as well as potential infectious issues from repeated mediastinal exploration for snare adjustment, must be considered. Pulmonary blood flow can be limited by the use of a 3.0-mm polytetrafluoroethylene shunt (Gore-Tex; W. L. Gore \& Associates, Inc, Flagstaff, Ariz); however, it is generally believed that such shunts are at increased risk of thrombosis and may require early reintervention as a result of worsening cyanosis. Hence, management of $\mathrm{Qp} / \mathrm{Qs}$, and particularly over-circulation, has been medical, with ventilator adjustment, use of systemic vasodilators, and support of overall cardiac output being the mainstays of therapy.

Although the using a right ventricular-pulmonary artery (RV-PA) conduit rather than a typical systemic-pulmonary artery shunt is one of the more recent and intriguing modifications to the Norwood procedure, RV-PA conduits have been described in place of classic systemic shunts in other congenital defects such as pulmonary atresia with ventricular septal defect and pulmonary atresia with intact ventricular septum. Although the first application of this technique to the Norwood 
operation is credited to Sano, the first publication including this technique was by Imoto and colleagues ${ }^{11}$ from Fukuoka, Japan. The first description of this technique at a major national or international meeting is credited to Sano, ${ }^{12}$ however. After these initial descriptions, the technique of the RV-PA conduit was quickly adopted by many surgeons. ${ }^{13}$ However, due to the short time frame during which this technique has been applied, long-term data are lacking.

In this issue of the Journal, Mair and colleagues ${ }^{14}$ describe their experience with what is now generally referred to as the "Sano" modification of the Norwood procedure. The findings are intriguing despite certain limitations of the study, such as a relatively small number of patients, short follow-up, and the use of historical controls.

The authors report an overall Norwood experience of 32 patients with the last 14 undergoing the RV-PA conduit modification. Although the in-house mortality was higher among the patients undergoing the standard Norwood procedure, it is important to remember that this was not a randomized study; in fact, the classic group represented the authors' earlier Norwood experience whereas the RV-PA conduit group represented their more recent experience. It is notable that a $3.5-\mathrm{mm}$ shunt was used in all group 1 patients despite the fact that 7 of the 18 patients weighed less than $3.0 \mathrm{~kg}$. It is the practice of many to use a $3.0-\mathrm{mm}$ shunt in patients weighing less than $3.0 \mathrm{~kg}$, which in theory would result in a lower $\mathrm{Qp} / \mathrm{Qs}$ in a manner similar to using an RV-PA conduit. However, the authors make a very valid point in that a smaller shunt is at increased risk of thrombosis, whereas presumably an RV-PA conduit, which is actually larger, is less likely to thrombose; in either case thrombosis is a rare occurrence.

Undoubtedly, the learning curve that all surgeons and institutions experience with a complex operation such as a Norwood procedure contributed to this mortality difference as much as, if not more than, the technique used. Furthermore, on closer examination it appears that only 2 of the 5 early deaths in the earlier group were clearly cardiac related. Nonetheless, based purely on subjective experience and impressions from other centers reporting mortality rates of around 30\% with the standard approach, improved early results have been seen with the RV-PA conduit modification. However, centers such as ours, where mortality for first-stage palliation of hypoplastic left heart syndrome is under $10 \%$ with the standard systemic-arterial shunt approach, have not seen a significant survival benefit nor an appreciable difference in hemodynamic stability or postoperative course with the RV-PA modification. A plausible explanation for the variation in results seen with this new modification relates as much to shunt size and experience with management of over-circulation as it does to the specific technique used.
Although improved early postoperative hemodynamics has been attributed to this technique, little objective data exist to support this. Mair and colleagues ${ }^{14}$ reported no significant difference in use of inotropic agents, urine output, or lactates in the early postoperative period between the 2 groups. Unfortunately, postoperative superior vena caval saturations were not measured and Qp/Qs was not calculated. The patients with the RV-PA shunts did appear to have lower overall pulmonary blood flow than those receiving the standard shunts, requiring higher inspired oxygen fractions to maintain comparable arterial oxygen tensions.

Although based purely on operative outcome and early hemodynamics there is little objective data supporting a benefit to the RV-PA modification. More intriguing, and perhaps compelling, data favoring this technique are demonstrated by the pre-Glenn catheterization data. The statistically significant finding of higher $\mathrm{dP} / \mathrm{dT}$ in the RV-PA conduit patients compared with the standard shunt approach patients has potentially significant long-term implications. Although once again taken in the context of a nonrandomized, consecutive series, it appears that no other modifications in operative technique, bypass, or myocardial protection were altered between the 2 groups to account for this difference. In a population of patients who are dependent on maintaining good function of the systemic right ventricle, improved systolic function in the RV-PA conduit group is the best supporting evidence to date in support of this technique. The authors imply that the improved $\mathrm{dP} / \mathrm{dT}$ may be a result of improved coronary perfusion as a result of higher diastolic pressures, which they did demonstrate. However, the effect of a higher diastolic pressure on coronary perfusion in these patients is purely conjecture because coronary perfusion was not measured and coronary blood flow is largely controlled by complex autoregulation.

Mair and colleagues ${ }^{14}$ demonstrate that indeed an RV-PA conduit can be used successfully and with good early results; however, a significant early or late survival advantage is not demonstrated. The improved $\mathrm{dP} / \mathrm{dT}$ on pre-Glenn catheterization is encouraging and may have implications regarding long-term ventricular function and outcome. However, this must be weighed against the potential risks of placing a ventriculotomy in a patient with a single ventricle. I congratulate the authors on their excellent results and thank them for contributing to the experience and understanding of this difficult group of patients and their management.

\section{References}

1. Norwood WI, Lang P, Hansen DD. Physiologic repair of aortic atresia-hypoplastic left heart syndrome. $N$ Engl J Med. 1983;308:23-6.

2. Drinkwater DC Jr, Aharon AS, Quisling SV, Dodd D, Reddy VS, Kavanaugh-McHugh A, et al. Modified Norwood operation for hypoplastic left hearts. Ann Thorac Surg. 2001;72:2081-6.

3. Pearl JM, Nelson DP, Schwartz SM, Manning PB. First-stage pallia- 
tion for hypoplastic left heart syndrome in the twenty-first century. Ann Thorac Surg. 2002;73:331-40.

4. Riordan CJ, Randsbeck F, Storey JH, Montgomery WD, Santamore WP, Austin EH III. Effects of oxygen, positive end-expiratory pressure, and carbon dioxide on oxygen delivery in an animal model of the univentricular heart. J Thorac Cardiovasc Surg. 1996;112:644-54.

5. Taeed R, Schwartz SM, Pearl JM. Unrecognized pulmonary venous desaturation early after Norwood palliation confounds Qp: Qs assessment and compromises oxygen delivery. Circulation. 2001;103:2699704.

6. Rossi AF, Sommer RJ, Lotvin A, Gross RP, Steinberg LG, Kipel G, et al. Usefulness of intermittent monitoring of mixed venous oxygen saturation after stage I palliation for hypoplastic left heart syndrome. Am J Cardiol. 1994;73:1118-23.

7. Barnes O, Santamore WP, Rossi A, Salloum E, Chein S, Austin EH Estimation of oxygen delivery in newborns with univentricular circulation. Circulation. 1998;98:1407-13.

8. Migliavacca F, Pennati G, Dubini G, Fumero R, Pietrabissa R, Urcelay $\mathrm{G}$, et al. Modeling of the Norwood circulation: effects of shunt size, vascular resistances, and heart rate. Am J Physiol Heart Circ Physiol. 2001;280:H2076-86.

9. Schmid FX, Kammann C, Kuroczynski W, Choi YH, Knuf M, Tza- nova I, et al. Adjustable tourniquet to manipulate pulmonary blood flow after Norwood operation. Ann Thorac Surg. 1999;68:2306-9.

10. Kuduvalli M, McLaughlin KE, Trivedi DB, Pozzi M. Norwood-type operation with adjustable systemic-pulmonary shunt using hemostatic clip. Ann Thorac Surg. 2001;72:5634-5.

11. Imoto Y, Kado H, Shiokawa Y, Minami K, Yasui H. Experience with the Norwood procedure without circulatory arrest. $J$ Thorac Cardiovasc Surg. 2001;122:879-82.

12. Sano S, Ishino K, Kawada M, Arai S, Kasahara S, Asai T, et al. Right ventricle-pulmonary artery shunt in first-stage palliation of hypoplastic left heart syndrome. J Thorac Cardiovasc Surg. 2003;126:504-10.

13. Harada Y, Oka N, Hiramatsu T, et al. Surgical results of Norwood first-stage operation for hypoplastic left heart syndrome: modified Blalock-Taussig shunt versus right ventricle to pulmonary artery shunt. Presented at the 39th annual meeting of The Society of Thoracic Surgeons, San Diego (CA), Jan 31-Feb 2, 2003.

14. Mair R, Tulzer G, Sames E, Gitter R, Lechner E, Steiner J, et al. Right ventricular to pulmonary artery conduit instead of modified BlalockTaussig shunt improves postoperative hemodynamics in newborns after the Norwood operation. J Thorac Cardiovasc Surg. 2003;126: $1378-84$

Access to The Journal of Thoracic and Cardiovascular Surgery Online is reserved for print subscribers!

Full-text access to The Journal of Thoracic and Cardiovascular Surgery Online is available for all print subscribers. To activate your individual online subscription, please visit The Journal of Thoracic and Cardiovascular Surgery Online, point your browser to http://www.mosby.com/jtcvs, follow the prompts to activate your online access, and follow the instructions. To activate your account, you will need your subscriber account number, which you can find on your mailing label (note: the number of digits in your subscriber account number varies from 6 to 10). See the example below in which the subscriber account number has been circled:

\section{Sample mailing label}

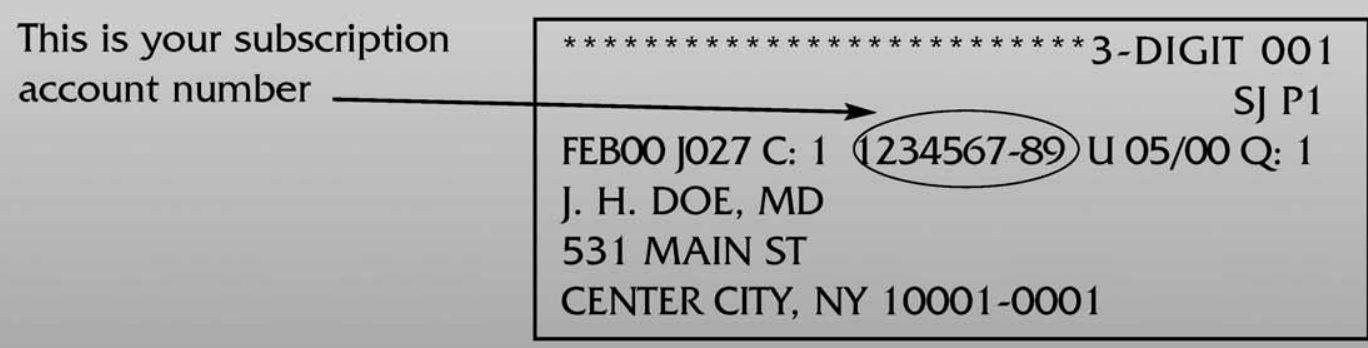

Personal subscriptions to The Journal of Thoracic and Cardiovascular Surgery Online are for individual use only and may not be transferred. Use of The Journal of Thoracic and Cardiovascular Surgery Online is subject to agreement to the terms and conditions as indicated online. 